\title{
Change in left ventricular geometry during antihypertensive treatment in children with primary hypertension
}

\author{
Joanna Śladowska-Kozłowska • Mieczyslaw Litwin • \\ Anna Niemirska • Aldona Wierzbicka • \\ Zbigniew T. Wawer • Roman Janas
}

Received: 12 February 2011 /Revised: 28 April 2011 / Accepted: 3 May 2011 /Published online: 31 May 2011

(C) The Author(s) 2011. This article is published with open access at Springerlink.com

\begin{abstract}
The pattern of the left ventricle (LV) has important significance in adults with hypertension. The aim of the present study was to analyze changes and determinants of LV geometry after 1 year of antihypertensive treatment in children with primary hypertension $(\mathrm{PH})$ in relation to metabolic abnormalities and anthropometrical parameters. In 86 children $(14.1 \pm 2.4$ years $)$ with newly diagnosed PH, LV geometry and biochemical parameters before and after 12 months of standard antihypertensive therapy were assessed. At baseline, normal LV geometry (NG) was found in $42(48.9 \%)$, concentric remodeling (CR) in $4(4.6 \%)$, concentric hypertrophy $(\mathrm{CH})$ in $8(9.3 \%)$, and eccentric hypertrophy $(\mathrm{EH})$ in $32(37.2 \%)$ patients. The prevalence of $\mathrm{NG}$ in patients with severe hypertension was
\end{abstract}

Electronic supplementary material The online version of this article (doi:10.1007/s00467-011-1916-8) contains supplementary material that is available to authorized users

J. Śladowska-Kozłowska • M. Litwin • A. Niemirska

Department of Nephrology and Arterial Hypertension,

The Children's Memorial Health Institute,

Warsaw, Poland

M. Litwin $(\bowtie)$

Department of Research,

The Children's Memorial Health Institute,

Aleja Dzieci Polskich 20,

04-736 Warsaw, Poland

e-mail: m.litwin@czd.pl

A. Wierzbicka $\cdot$ Z. T. Wawer

Department of Biochemistry and Experimental Medicine,

The Children's Memorial Health Institute,

Warsaw, Poland

R. Janas

Department of Radioimmunology,

The Children's Memorial Health Institute,

Warsaw, Poland significantly lower than in patients with ambulatory hypertension. There were no differences in dipping status in relation to LV geometry. Patients with $\mathrm{CH}$ and $\mathrm{EH}$ were more viscerally obese than patients with NG. Patients with $\mathrm{CH}$ had higher diastolic blood pressure in comparison with EH patients $(p<0.05)$. The main predictor of relative wall thickness (RWT) was the triglycerides to high density lipoprotein cholesterol (TG/HDL) ratio $\left(R^{2}=0.319, \beta=\right.$ $0.246, p=0.004)$. Patients received 12 months of antihypertensive treatment, either lifestyle modification only $(n=$ 37 ) or lifestyle modification plus antihypertensive medications $(n=49)$ if severe ambulatory hypertension or target organ damage were present. After 12 months of treatment the prevalence of EH $(37.2 \%$ vs $18.6 \%, p=0.003)$ decreased but prevalence of $\mathrm{CH}$ did not change. Patients in whom RWT decreased also decreased waist circumference and TG/HDL; the main predictor of RWT decrease was a decrease of the TG/HDL ratio $\left(\beta=0.496, R^{2}=0.329\right.$, $p=0.002)$. In adolescents with $\mathrm{PH}, \mathrm{LV}$ geometry is related to central obesity and insulin resistance. Decrease of abdominal obesity and insulin resistance are the most important predictors of normalization of LV geometry, however $\mathrm{CH}$ has lower potential to normalize LV geometry.

Keywords Primary hypertension - Left ventricular hypertrophy - Left ventricular remodeling · Antihypertensive treatment . Children

\section{Introduction}

Subclinical target organ damage (TOD) is present in 30 $40 \%$ of children with primary hypertension $(\mathrm{PH})$ at the diagnosis of elevated blood pressure (BP) [1-5] and correlates with metabolic abnormalities, central obesity, 
and prevalence of metabolic syndrome (MS) [6-8]. This has clinical importance because of increased cardiovascular morbidity in adults with TOD [9, 10]. Left ventricular hypertrophy (LVH) is the most clinically useful marker of TOD. The left ventricle (LV) may adapt to hypertension by developing concentric or eccentric LVH $(\mathrm{CH}$, EH respectively), concentric left ventricular remodeling (CR), or by retaining normal LV geometry (NG). Each geometric pattern is associated with a distinct combination of pressure and volume stimuli, contractile and diastolic efficiency (reduced in those with $\mathrm{CR}$ or $\mathrm{CH}$ ) and prognosis (worst with $\mathrm{CH}$ and best with NG) $[11,12]$. The relation between LV remodeling and metabolic abnormalities in children with PH has not been fully explored [13].

To date, there are only limited data on the effectiveness of antihypertensive treatment in adolescents with $\mathrm{PH}$ and even fewer data exist on the regression of LVH and changes in geometric abnormalities [14-16]. Previously, we found that the main determinant of $\mathrm{LVH}$ regression was a decrease in visceral obesity [16]. The aim of the present study was to analyze changes and determinants of LV geometry after 1 year of antihypertensive treatment in the same group of children with $\mathrm{PH}$ in relation to metabolic abnormalities and anthropometrical parameters.

\section{Patients and methods}

The study adhered to the principles of the Declaration of Helsinki and was approved by the local Ethics Committee. All parents and children who were literate and able to understand age-based patient information provided written informed consent.

\section{Patients}

The study group has already been described [16]. In short, 86 children (20 girls) with untreated $\mathrm{PH}$, mean age 14.1 (range: 5-17 years) and who completed all investigative procedures, were enrolled onto the study. PH was diagnosed after a thorough clinical and laboratory diagnostic work-up, according to recently published recommendations $[17,18]$. The exclusion criteria were: diagnosis of secondary hypertension, previous use of antihypertensive drugs, presence of any significant chronic disease (except for $\mathrm{PH})$, any acute disease, including infections, in the 6 weeks preceding enrollment, and incomplete data.

Normal office blood pressure values were taken from the Updated 4th Task Force Report [17]. In all patients the diagnosis was confirmed by 24-h ambulatory blood pressure monitoring (ABPM). ABPM was performed at the initial visit and after 12 months. Recordings lasting at least $20 \mathrm{~h}$ with at least $80 \%$ of records considered valid.
Blood pressure values were calculated from the ABPM data as the mean 24-h systolic (SBP) and diastolic (DBP) blood pressure and presented as absolute values and as systolic and diastolic blood pressure indices (SBPI and DBPI respectively) calculated as the ratio of SBP or DBP to the 95th percentile for age and gender based on the pediatric ABPM reference data [19]. We used a recently published classification system based on ABPM to classify patients as having normal blood pressure, ambulatory hypertension, or severe ambulatory hypertension [20].

Methods

All patients underwent the following assessments: anthropometrical measurements including body mass index (BMI), waist circumference (WC), waist-to-hip ratio (WHR) and waist-to-height ratio (WHTR), echocardiography, urinary albumin excretion, serum glucose and insulin, blood lipids, serum homocysteine, serum uric acid and C-reactive protein (hsCRP), and serum asymmetric dimethylarginine (ADMA) concentrations. In addition, in all patients oxidative stress markers, i.e., thiobarbituric acid reactive substances (TBARS), oxidized LDL-cholesterol (oxyLDL) concentrations, and anti-oxidative defense (reduced glutathione concentration [GSH], glutathione peroxidase activity [GPX]) were measured. Obesity and overweight was diagnosed according to International Obesity Task Force recommendations [21]. Because some of our patients were below 10 years of age, metabolic syndrome was diagnosed as described previously, and when at least three criteria were present (BMI $\geq 95$ th percentile for age and gender, arterial hypertension, serum triglycerides $>110 \mathrm{mg} / \mathrm{dl}$, fasting plasma glucose $>100 \mathrm{mg} / \mathrm{dl}$ or $>140 \mathrm{mg} / \mathrm{dl}$ at $2 \mathrm{~h}$ of oral glucose tolerance test and HDL cholesterol $<40 \mathrm{mg} / \mathrm{dl}$ ) [6].

\section{Echocardiography}

All echocardiography (ECHO) examinations were performed by one examiner who knew the clinical diagnosis, but was not aware of the severity of $\mathrm{PH}$ or effectiveness of treatment. ECHO measurements were performed according to the American Society of Echocardiography guidelines [22, 23]. To standardize left ventricular mass to height, the left ventricular mass index (LVMi) was calculated according to the deSimone formula [24]. LVH was defined as an LVMi value above 95th percentile for age and gender based on the pediatric LVMi reference data of Khoury's [25]. Relative wall thickness (RWT) was measured at end diastole as the ratio of posterior wall thickness plus interventricular septum thickness over LV internal dimension. A RWT of 0.41, which represents the 95th percentile for RWT for normal children and adolescents, and the 95th percentile of LVMi for age and gender for normal children and adolescents were 
used as cut-off points in the evaluation of LV geometry [26]. Normal geometry was defined as RWT $<0.41$ and LVMi $<$ value of 95 th percentile, RWT $<0.41$ and $L V M i>$ value of 95th percentile of LVMi defined EH, RWT $>0.41$ and LVMi $>$ value of 95th percentile of LVMi defined $\mathrm{CH}$, and RWT $>0.41$ and $\mathrm{LVMi}<95$ th percentile of LVMi defined CR.

\section{Laboratory investigations}

Blood samples were taken after $12 \mathrm{~h}$ of fasting and were immediately sent to the laboratory. Plasma glucose levels were measured using a Dimension analyzer. Plasma insulin concentrations and glycated hemoglobin ( $\mathrm{HbAlC}$ ) were measured by radioimmunoassay. Oral glucose tolerance test was carried out in all patients after oral ingestion of $1 \mathrm{~g} / \mathrm{kg}$ body weight (maximum $75 \mathrm{~g}$ ) of glucose. Insulin resistance was expressed as homeostasis model assessment for insulin resistance (HOMA-IR) and as a triglycerides to high density lipoprotein cholesterol (TG/HDL) ratio [27, 28]. The hsCRP concentration was assayed using a highlysensitive immunoturbidimetry kit (Orion Diagnostica). Plasma lipid peroxides were determined with the spectrofluorometric method of Yagi and expressed as thiobarbiturate reactive substance $(\mathrm{nmol} / \mathrm{ml})$. Glutathione and glutathione peroxidase activity were used as indicators of antioxidant status and were measured spectrophotometrically in erythrocytes (GSH-420(Oxis) and GPx-340(Oxis)). OxyLDL and asymmetric dimethyloarginine (ADMA) concentrations were measured by ELISA using a commercially available kit. Urinary albumin excretion in 24-h samples was determined by the immunonephelometric method. The laboratory procedures have been described in detail in a previous study [6].

\section{Antihypertensive treatment}

The principles of treatment were the same as previously described [16]. In short, pharmacological treatment was started in patients who had significant TOD and/or severe ambulatory hypertension. BP was checked at 3 and 6 months during ambulatory visits. If after 3 or 6 months office BP was still within the hypertensive range, ABPM was carried out. In patients who still had ambulatory or severe ambulatory hypertension, pharmacotherapy was started or another drug was given. Finally, in all patients ABPM was done after 12 months of treatment. Patients who after 12 months of treatment lowered ABPM to below the 95th percentile were treated as responders and those who did not, as non-responders. Drug therapy was based on an angiotensin converting enzyme inhibitor (ACEi), enalapril $(0.2-0.3 \mathrm{mg} / \mathrm{kg} /$ day bid). Patients who had asthma or did not tolerate ACEi were prescribed an angiotensin 2 receptor type 1 blocker (ARB), losartan $(0.7-1 \mathrm{mg} / \mathrm{kg} /$ day in one or two daily doses). If patients were unable to buy the prescribed medications (enalapril or losartan), amlodipine was used at a standard dose of $5 \mathrm{mg}$ once daily. Detailed descriptions of the principles of treatment are shown in the Electronic Supplementary Material (ESM).

\section{Statistical analysis}

Because the analyzed groups included subjects of different ages and genders, BMI and WC values were expressed both as absolute values and as SDS for age and gender. LVM values in grams were standardized to height in meters ${ }^{2.7}$. The change of measured parameters was expressed as a delta value $(\Delta)$, i.e., the difference between measurement at 12 months and at the start of treatment. Homogeneity of variance was checked with the Levene test. Continuous variables with a normal distribution were compared using Student's $t$ test for independent variables. Continuous values with non-normal distribution were compared using the Mann-Whitney $U$ test. Comparison between groups was evaluated with ANOVA test using Bonferroni correction. Measurements taken at the start and after 12 months of treatment were compared using the Wilcoxon test. Dichotomous variables were compared using the Chi-squared test and change in prevalence during treatment was analyzed with the McNemar test. Correlation analysis was carried out with the Spearman test. RWT and $\Delta$ for RWT were dependent variables. Variables with significant correlation or that differed between groups of patients in whom LV geometry was normalized or not, were then included in the step-wise multiple regression analysis. A $p$ value less than 0.05 was regarded as statistically significant. A $p$ value ranging between 0.05 and 0.1 was regarded as a statistical tendency.

\section{Results}

Descriptive demographic, clinical, and laboratory data obtained at the start and after 12 months of treatment are summarized in Table S1 (ESM).

First evaluation

According to the International Obesity Task Force criteria, $67 \%$ of patients were obese or overweight (58 patients). Fortytwo (48.9\%) patients had NG, 4 (4.6\%) had CR, 8 (9.3\%) had $\mathrm{CH}$, and $32(37.2 \%) \mathrm{EH}$. Patients with $\mathrm{CH}$ and $\mathrm{EH}$ were more viscerally obese than patients with NG (Table 1). Patients with $\mathrm{CH}$ in comparison with patients with $\mathrm{EH}$ had greater DBP and a tendency towards a greater birth weight $(p=0.1)$. EH was more prevalent among obese than non-obese patients. Patients with severe ambulatory hypertension $(n=36)$ had greater LVMi than patients with ambulatory hypertension $\left(n=50 ; 42.3 \pm 12.1 \mathrm{~g} / \mathrm{m}^{2.7}\right.$ vs $\left.35.7 \pm 8.7 \mathrm{~g} / \mathrm{m}^{2.7}, p<0.01\right)$ and 
Table 1 Descriptive demographic, clinical and laboratory data according to the left ventricular geometric pattern at the first evaluation. Only significant differences $(p<0.05)$ or statistical tendencies $(p$ in the range $0.05-0.1)$ are shown

\begin{tabular}{|c|c|c|c|c|c|}
\hline & NG1 42 (48.9\%) & CR1 $4(4.6 \%)$ & CH1 8 (9.3\%) & EH1 $32(37.2 \%)$ & $p$ \\
\hline Birth weight $(\mathrm{g})$ & $3,400(1,410-4,100)$ & $3,495(3,130-3,850)$ & $3875(2850-5300)$ & $3300(2100-5250)$ & $\begin{array}{l}\text { NG1 vs } \mathrm{CH} 1<0.01 \\
\mathrm{CH} 1 \text { vs } \mathrm{EH} 1<0.11\end{array}$ \\
\hline BMI $\left(\mathrm{kg} / \mathrm{m}^{2}\right)$ & $23.9(15.2-39.7)$ & $20.7(18.9-22.8)$ & $25.9(21.9-27.9)$ & $27.1(19.8-39.1)$ & NG1, CR1 vs EH1 <0.05 \\
\hline $\mathrm{WC}(\mathrm{cm})$ & $78(53-98.5)$ & $75(67-80)$ & $87(78-96)$ & $93(66-111)$ & $\begin{array}{l}\text { NG1 vs CH1, EH1 }<0.05, \\
\text { CR1 vs CH1, EH1 }<0.05\end{array}$ \\
\hline WHR & $0.81(0.72-0.91)$ & $0.89(0.78-0.97)$ & $0.87(0.78-1.03)$ & $0.88(0.73-1.03)$ & $\begin{array}{l}\text { NG1 vs } \mathrm{EH} 1<0.01 \\
\mathrm{NG} 1 \text { vs } \mathrm{CH} 1=0.07\end{array}$ \\
\hline $\begin{array}{l}\text { Patients with ambulatory } \\
\text { hypertension }(\%)\end{array}$ & $29(69 \%)$ & $2(50 \%)$ & $4(50 \%)$ & $15(46.8 \%)$ & $\begin{array}{l}\text { NG1 vs EH1 0.05, } \\
\text { Chi-squared }=3.70\end{array}$ \\
\hline $\begin{array}{l}\text { Patients with severe } \\
\text { ambulatory } \\
\text { hypertension }\end{array}$ & $13(31 \%)$ & $2(50 \%)$ & $4(50 \%)$ & $17(53.1 \%)$ & $\begin{array}{l}\text { NG1 vs EH1 0.05, } \\
\text { Chi-squared }=3.70\end{array}$ \\
\hline Total cholesterol (mg/dl) & $178(100-290)$ & $192(181-243)$ & $177(130-205)$ & $168(94-236)$ & CR1 vs EH1 $<0.05$ \\
\hline HDL (mg/dl) & $44(25-58)$ & $49(46-50)$ & $44(22-66)$ & $42(29-61)$ & CR1 vs $\mathrm{EH} 1<0.05$ \\
\hline $\mathrm{HbA1C}(\%)$ & $5.4(4.5-6.7)$ & $4.9(4.2-5.0)$ & $5.0(4.4-5.4)$ & $5.3(4.1-6.8)$ & $\begin{array}{l}\text { CR1 vs NG1 0.05, } \\
\text { vs EH1 } 0.06\end{array}$ \\
\hline Insulin[0] (mU/ml) & $13(5.6-31)$ & $13.5(5-16)$ & $11.7(9.3-39)$ & $13.6(7.5-48)$ & $\begin{array}{l}\text { CH1 vs CR10.10, } \\
\text { CH1 vs EH1 0.11 }\end{array}$ \\
\hline Uric acid (mg/dl) & $5.4(2.7-8.6)$ & $5(4.2-5.6)$ & $5.6(3.2-7.5)$ & $5.6(3.2-8.3)$ & ns \\
\hline GPX (U/g Hb) & $31.2(26.1-39.9)$ & $30.2(25.4-31.6)$ & $32.6(29.1-38.7)$ & $31.8(26.2-38.1)$ & $\begin{array}{l}\text { CR1 vs CH1 }<0.05, \\
\text { CR1 vs EH10.06 }\end{array}$ \\
\hline $\begin{array}{l}\text { Thiobarbiturate reactive } \\
\text { substance }(\mu \mathrm{mol} / \mathrm{l})\end{array}$ & $0.24(0.16-1.25)$ & $0.42(0.34-0.62)$ & $0.30(0.14-1.28)$ & $0.32(0.18-1.25)$ & NG1 vs $\mathrm{CR} 1, \mathrm{EH} 1<0.05$ \\
\hline $\begin{array}{l}\text { Overweight and obese } \\
\text { patients (\%) }\end{array}$ & $23(54.8 \%)$ & $1(25 \%) 0$ & $8(100 \%)$ & $26(81.2 \%)$ & $\begin{array}{l}\text { NG1 vs EH1 } 0.01 \\
\text { Chi-squared=5.7, NG1 } \\
\text { vs CH1 0.04, Chi-squared= } \\
\text { 4.07, CR1 vs CH1 0.03, } \\
\text { Chi-squared }=4.50\end{array}$ \\
\hline
\end{tabular}

NG1, normal geometry at start of treatment; CR1, concentric remodeling at start of treatment; CH1, concentric hypertrophy at start of treatment; EH1, eccentric hypertrophy at start of treatment; HDL, high-density lipoprotein cholesterol; LDL, low-density lipoprotein cholesterol; HbA1C, glycated hemoglobin; glucose[0], fasting glucose concentration; GPX, glutathione peroxidase activity

there was a tendency towards a higher prevalence of LVH $(58 \%$ vs $38 \%$, Chi-squared $=3.48, p=0.06)$. The prevalence of NG in patients with severe ambulatory hypertension was significantly lower (13 patients, $36.1 \%$ vs 29 patients, $58 \%, p=0.04$, Chi-squared $=4.01$ ). Patients with ambulatory and severe ambulatory hypertension did not differ in terms of RWT. There were no differences regarding dipping profiles among patients with different patterns of LV geometry. RWT correlated with WHR $(p<$ $0.05, r=0.25)$, TG/HDL ratio $(p<0.05, r=0.29)$, and TBARS concentration $(p<0.01, r=0.35)$. The main predictor of RWT was the TG/HDL ratio $\left(R^{2}=0.319, \beta=\right.$ $0.246, p=0.0004$ ), and the main predictor of LVMi was WC $\left(R^{2}=0.279, \beta=0.561, p=0.008\right)$.

Second evaluation after 12 months

Throughout the study, 37 (43\%) patients were prescribed only non-pharmacological therapy, including dietary advice and increased physical activity. Thirty-four (39.5\%) patients received one antihypertensive medication, 9 patients (10.5\%) received two drugs (ACEi or ARB plus amlodipine), and $6(7 \%)$ received three drugs (ACEi or ARB plus amlodipine and metoprolol). As reported earlier, overall after 12 months, BP normalized below the 90th percentile in 54 $(62.8 \%)$ patients, 10 patients were in the pre-hypertensive range (11.6\%), 21 (24.4\%) patients had ambulatory hypertension, and 1 (1.2\%) had severe ambulatory hypertension, but the decrease in hypertension severity was significant [16]. The prevalence of LVH decreased from $40(46.5 \%)$ to $24(27.9 \% ; p=0.003$; Chi-squared $=8.65)$. RWT decreased in 41 patients and LVMi in 58 patients. The number of patients with NG increased (to 56 patients), and that of patients with $\mathrm{EH}$ decreased (to 16 patients) significantly (Table S1 ESM). Of 42 patients who had NG at first examination, 34 still had NG after 12 months. The 8 patients who developed abnormal LV geometry (3 $\mathrm{CR}, 2 \mathrm{CH}$, and $3 \mathrm{EH})$ had a significantly 
greater BMI, BMI-SDS, WC, uric acid concentration and lower HDL than patients who still had NG (Table 2). Of 32 patients with $\mathrm{EH}$ at first examination, after 12 months 16 patients still had abnormal LV geometry (1 CR, $4 \mathrm{CH}$, $11 \mathrm{EH})$ and 16 patients $(50 \%)$ had $\mathrm{NG}$-patients who normalized LV geometry had a tendency toward a lower visceral fat accumulation in comparison with patients who still had LVH (Table 2). Three (75\%) of the 4 patients with CR normalized LV geometry after 12 months and 3 patients $(37.5 \%)$ with $\mathrm{CH}$ at first examination also moved to the NG group after 12 months.

Patients who still had CH had greater DBP (73 [68-93] vs 68 [58-79] mmHg, $p=0.03)$, DBPI $(0.94$ [0.88-1.22] vs 0.86 [0.01-1.02], $p=0.02)$ and GPX (31.6 [30.8-32.7] vs 30.5 [29.9-34.5] U/gHb, $p=0.04$ ) in comparison with patients who had EH. Similarly, patients who still had $\mathrm{CH}$ or who developed abnormal geometry had greater insulin concentrations during the oral glucose tolerance test and greater HbA1C after 1 year (Table 2). The decrease in DBP, DBPI, and TG/HDL ratio after 12 months in patients with $\mathrm{CH}$ was significantly lower than in patients with $\mathrm{EH}$ and in patients with NG. Also, the decrease in uric acid concentrations in patients with $\mathrm{CH}$ was lower than in patients with EH (Table 3). In general, patients who had lowered RWT decreased $\mathrm{WC}$ and the $\mathrm{TG} / \mathrm{HDL}$ ratio to a significantly greater extent than patients with an increase or stabilization of RWT (Table 4). The prevalence of metabolic syndrome decreased in the subgroup of patients who had decreased RWT in comparison with the subgroup of patients with progression/stabilization of RWT. Similarly, the prevalence of metabolic syndrome decreased ( 8 vs 1 case) only in the group of 58 patients who had decreased LVMi $(p=0.02$; Chi-squared=5.14). On the contrary, the prevalence of metabolic syndrome did not change among patients who did not have a decrease in LVMi. The decrease in RWT correlated with decreases in WC $(r=0.25, p<0.05)$, TG/ HDL ratio $(r=0.38, p<0.01)$, albuminuria $(r=0.32, p<0.05)$, as well as with values of the TG/HDL ratio $(r=-0.26, p<$ $0.01)$, RWT ( $r=-0.64, p<0.001)$, and LVMi $(r=-0.35, p<$ $0.001)$ at the first evaluation and thiobarbiturate reactive substance concentration at the first and the second evaluation ( $r=-0.22, p<0.05$ and $r=-0.21, p<0.05$ respectively). The main predictor of RWT decrease was a decrease in the TG/HDL ratio $\left(\beta=0.496, R^{2}=0.329, p=0.002\right)$.

\section{Discussion}

There are three main findings of our study. First, EH is the most frequently found pattern of LV remodeling in

Table 2 Differences between patients with normal left ventricular geometry and patients who had abnormal left ventricular geometry after 12 months. $p$ Values of statistical significance $(<0.05)$ and tendency $(0.05-0.1)$ are shown

\begin{tabular}{|c|c|c|c|c|}
\hline \multirow[t]{2}{*}{ First examination } & \multicolumn{4}{|l|}{ Second examination } \\
\hline & & NG & Abnormal geometry & $p$ \\
\hline \multirow[t]{10}{*}{$\mathrm{NG}-42$ patients } & $n$ & 34 & $8(3 \mathrm{CR}, 2 \mathrm{CH}, 3 \mathrm{EH})$ & \\
\hline & BMI $\left(\mathrm{kg} / \mathrm{m}^{2}\right)$ & $23.3(15.3-36.3)$ & $27.4(19.7-33.5)$ & 0.003 \\
\hline & BMI-SDS & $0.93(-0.93-5.74)$ & $2.368-0.46-5.26)$ & 0.006 \\
\hline & $\mathrm{WC}(\mathrm{cm})$ & $78.5(52-101)$ & $89(71.5-102)$ & 0.02 \\
\hline & WC-SDS & $0.96(-1.72-3.71)$ & $1.91(-0.66-4.94)$ & 0.03 \\
\hline & WHR & $0.81(0.68-0.97)$ & $0.87(0.70-0.91)$ & 0.04 \\
\hline & WHtR & $0.46(0.37-0.56)$ & $0.53(0.41-0.57)$ & 0.006 \\
\hline & Uric acid (mg/dl) & $4.9(3.0-7.7)$ & $6.4(3.9-6.7)$ & 0.04 \\
\hline & HDL (mg/dl) & $47(29-66)$ & $37.5(30-47)$ & 0.01 \\
\hline & HbA1C (\%) & $5.2(4.7-9.8)$ & $5.5(5.4-7.5)$ & 0.03 \\
\hline $\mathrm{CR}-4$ patients & $n$ & 4 & $1(\mathrm{CR})$ & \\
\hline \multirow[t]{3}{*}{$\mathrm{CH}-8$ patients } & $n$ & 3 & $5(1 \mathrm{CR}, 2 \mathrm{CH}, 2 \mathrm{EH})$ & \\
\hline & Insulin[120] (mU/ml) & $28.9(25-35)$ & $47(31.1-90)$ & 0.05 \\
\hline & $\Delta$ Insulin[120] $(\mathrm{mU} / \mathrm{ml})$ & $-19(-48-(-0.1))$ & $24(0-29.3)$ & 0.02 \\
\hline \multirow[t]{2}{*}{$\mathrm{EH}-32$ patients } & $n$ & 16 & $16(1 \mathrm{CR}, 4 \mathrm{CH}, 11 \mathrm{EH})$ & \\
\hline & GSH & 780.7 (694.1-821.7) & $758.5(638.1-819.3)$ & 0.09 \\
\hline
\end{tabular}

Abbreviations: $n$, number of patients; NG, normal geometry of left ventricle; $\mathrm{CR}$, concentric remodeling; $\mathrm{CH}$, concentric hypertrophy; EH, eccentric hypertrophy; BMI, body mass index; WC, waist circumference; WHR, waist to hip ratio; WHtR, waist to high ratio; HbA1C, glycated hemoglobin concentration; insulin[120], insulin concentration after 120 min of oral glucose ingestion; HDL, high density lipoprotein cholesterol; $\mathrm{GSH}$, reduced glutathione; SDS, standard deviation score 
Table 3 Differences between patients with a different left ventricular geometric pattern in the second examination. $p$ Values of statistical significance $(<0.05)$ and tendency $(0.05-0.1)$ are shown

\begin{tabular}{|c|c|c|c|c|c|}
\hline & NG2 & $\mathrm{CR} 2$ & $\mathrm{CH} 2$ & $\mathrm{EH} 2$ & $p$ \\
\hline Number of patients $(\%)$ & $56(65.1 \%)$ & $6(7 \%)$ & $8(9.3 \%)$ & $16(18.6 \%)$ & \\
\hline$\Delta$ BMI $\left(\mathrm{kg} / \mathrm{m}^{2}\right)$ & $0.49(-8.54-3.48)$ & $0.42(-1.73-2.30)$ & $0.55(-1.97-7.69)$ & $0.09(-5.63-5.14)$ & ns \\
\hline$\Delta$ BMI-SDS & $0.11(-5.26-1.23)$ & $-0.16(-0.52-0.72)$ & $-0.16(-0.92-2.61)$ & $0.13(-1.76-1.60)$ & ns \\
\hline$\Delta \mathrm{WC}(\mathrm{cm})$ & $0.25(-23.5-8.5)$ & $-0.75(-7-3.5)$ & $-1.5(-4.5-18.5)$ & $-2.5(-17-4)$ & NG2 vs EH20.02 \\
\hline$\Delta$ WC-SDS & $-0.13(-4.04-0.99)$ & $-0.29(-1.45-0.03)$ & $-0.39(-0.98-1.97)$ & $-0.45(-2.22-0.50)$ & NG2 vs EH20.05 \\
\hline$\Delta \mathrm{WHR}$ & $0(-0.01-0.09)$ & $-0.02(-0.09-0.01)$ & $-0.01(-0.09-0.09)$ & $-0.02(-0.18-0.04)$ & ns \\
\hline$\Delta \mathrm{WHtR}$ & $0(-0.14-0.05)$ & $-0.01(-0.09-0.02)$ & $-0.01(-0.06-0.09)$ & $-0.03(-0.10-0.01)$ & NG2 vs EH2 0.007 \\
\hline$\Delta \mathrm{SBP} / 24 \mathrm{~h}(\mathrm{mmHg})$ & $-5(-33-20)$ & $-3(-18-12)$ & $-2(-13-7)$ & $-1(-19-4)$ & ns \\
\hline$\Delta \mathrm{SBPI} / 24 \mathrm{~h}$ & $-0.05(-0.29-0.27)$ & $-0.03(-0.14-0.09)$ & $-0.02(-0.16-0)$ & $-0.04(-1.01-0.01)$ & ns \\
\hline$\Delta \mathrm{DBP} / 24 \mathrm{~h}(\mathrm{mmHg})$ & $-2(-30-19)$ & $1(-13-4)$ & $5(-15-23)$ & $-2(-13-4)$ & $\begin{array}{l}\mathrm{CH} 2 \text { vs } \mathrm{NG} 2, \mathrm{EH} 2<0.05 \\
\mathrm{CH} 2 \text { vs } \mathrm{CR} 20.10\end{array}$ \\
\hline$\Delta \mathrm{DBPI} / 24 \mathrm{~h}$ & $-0.03(-1.04-0.25)$ & $0.01(-0.16-0.05)$ & $0.06(-0.20-0.30)$ & $-0.03(-0.77-0.13)$ & $\begin{array}{l}\mathrm{CH} 2 \text { vs } \mathrm{NG} 2, \mathrm{EH} 2<0.05 \\
\mathrm{CH} 2 \text { vs } \mathrm{CR} 20.15\end{array}$ \\
\hline$\Delta \mathrm{TG} / \mathrm{HDL}$ & $-0.11(-5.77-2.63)$ & $-0.04(-1.59-0.85)$ & $0.94(-0.77-4.41)$ & $-0.12(-2.45-1.50)$ & $\mathrm{CH} 2$ vs $\mathrm{NG} 2, \mathrm{EH} 2<0.05$ \\
\hline$\Delta$ HOMA-IR & $-0.10(-3.71-8.14)$ & $-0.70(-2.23-0.69)$ & $1.34(-0.66-4.05)$ & $0.01(-1.47-0.59)$ & $\begin{array}{c}\mathrm{CH} 2 \text { vs } \mathrm{CR} 2<0.05 \text {, } \\
\mathrm{CH} 2 \text { vs } \mathrm{NG} 20.1\end{array}$ \\
\hline$\Delta$ uric acid $(\mathrm{mg} / \mathrm{dl})$ & $-0.1(-2.7-0.8)$ & $0.2(-0.5-1.6)$ & $0.1(-0.2-2)$ & $-0.7(-2.4-2.7)$ & $\begin{array}{l}\mathrm{EH} 2 \text { vs. } \mathrm{CH} 2, \mathrm{CR} 2<0.05, \\
\mathrm{EH} 2 \text { vs NG20.05, }\end{array}$ \\
\hline$\triangle \mathrm{ADMA}$ & $-0.06(-0.58-0.53)$ & $-0.11(-0.33-0.07)$ & $0.33(0.08-0.91)$ & $-0.14(-0.91-0.30)$ & $\begin{array}{l}\mathrm{CH} 2 \text { vs } \mathrm{NG} 2, \mathrm{CR} 2<0.05 \\
\mathrm{CH} 2 \text { vs } \mathrm{EH} 20.08\end{array}$ \\
\hline
\end{tabular}

NG2, normal geometry after 12 months of antihypertensive treatment; CR2, concentric remodeling after 12 months of antihypertensive treatment; $\mathrm{CH} 2$, concentric hypertrophy after 12 months of antihypertensive treatment; EH2, eccentric hypertrophy after 12 months of antihypertensive treatment; BMI, body mass index; WC, waist circumference; WHR, waist to hip ratio; WHtR, waist to high ratio; SBP/24h, mean systolic blood pressure in 24-h ambulatory blood pressure monitoring; SBPI/24h, index of mean systolic blood pressure in 24-h ambulatory blood pressure monitoring; DBP/24h, mean diastolic systolic blood pressure in 24-h ambulatory blood pressure monitoring; DBPI/24h, index of mean diastolic systolic blood pressure in 24-h ambulatory blood pressure monitoring; TG/HDL, triglycerides to high-density lipoprotein cholesterol ratio; HOMA-IR, homeostasis model assessment for insulin resistance; ADMA, serum asymmetric dimethyloarginine; SDS, standard deviation score

Table 4 Differences between patients with regression of relative wall thickness (RWT) and in whom RWT was stable or increased. $p$ Values of statistical significance $(<0.05)$ and tendency $(0.05-0.1)$ are shown

\begin{tabular}{|c|c|c|c|}
\hline & $\begin{array}{l}\text { Decrease of RWT, } \\
n=41\end{array}$ & $\begin{array}{l}\text { Increase or stabilization } \\
\text { of RWT, } n=45\end{array}$ & $p$ \\
\hline$\Delta \mathrm{WC}(\mathrm{cm})$ & $-1.5(-23.5-8.5)$ & $0(-8-18.5)$ & 0.029 \\
\hline$\Delta \mathrm{TG} / \mathrm{HDL}$ & $-0.10(-5.77-1.47)$ & $-0.07(-1.59-4.41)$ & 0.03 \\
\hline$\Delta \operatorname{LVMi}\left(\mathrm{g} / \mathrm{m}^{2.7}\right)$ & $-7.4 \pm 7.3$ & $0.5 \pm 6.6$ & $<0.0001$ \\
\hline$\Delta$ urinary albumin excretion $(\mathrm{mg} / 24 \mathrm{~h})$ & $-3.4(-269.4-52)$ & $-0.9(-103.3-128)$ & 0.1 \\
\hline RWT1 (mm) & $0.38(0.23-0.67)$ & $0.32(0.25-0.41)$ & 0.0001 \\
\hline RWT2 (mm) & $0.33(0.21-0.46)$ & $0.36(0.29-0.49)$ & $<0.001$ \\
\hline $\operatorname{LVMi1}\left(\mathrm{g} / \mathrm{m}^{2.7}\right)$ & $41.7 \pm 10.1$ & $35.5 \pm 10.6$ & 0.008 \\
\hline LVMi2 $\left(\mathrm{g} / \mathrm{m}^{2.7}\right)$ & $34.2 \pm 6.8$ & $36.2 \pm 8.2$ & $\mathrm{~ns}$ \\
\hline $\begin{array}{l}\text { Number of patients with metabolic syndrome } \\
\text { at start of treatment }\end{array}$ & $7 *$ & 6 & ns \\
\hline $\begin{array}{l}\text { Number of patients with metabolic syndrome } \\
\text { after } 12 \text { months of treatment }\end{array}$ & $1 *$ & 5 & ns \\
\hline
\end{tabular}

RWT, relative wall thickness (RWT1, at start of treatment; RWT2, after 12 months of treatment); $n$, number of patients; WC, waist circumference; TG/HDL, triglycerides to high-density lipoprotein cholesterol ratio; LVMi, left ventricular mass index; LVMi1, at start of treatment; LVMi2, after 12 months of treatment

${ }^{*} p=0.04$, Chi-squared $=4.17$ 
adolescents with PH. Second, the main determinants of pathological remodeling of the $\mathrm{LV}$ are visceral obesity and metabolic abnormalities. Third, both LVH and EH can be reversed and LV geometry can fully normalize; however, $\mathrm{CH}$ has less potential to normalize LV geometry.

Daniels et al. already found that EH was the most frequent pathological pattern of LV remodeling [1]. This type of LV remodeling is typical for states of volume overload or as a consequence of long-standing cardiac disease and heart failure [10, 11]. However, EH is also typical for obesity, and obesity is the dominant intermediate phenotype of children with PH $[6,29]$. EH was also found to be the most prevalent form of LVH in other studies in hypertensive adolescents and young adults with relatively short durations of PH. In the Strong Heart Study, in which as many as $65 \%$ of patients had a BMI above 30 , EH was present in $20 \%$ of patients aged $14-39$ with $\mathrm{PH}$, and $\mathrm{CH}$ occurred in just a few of them [30]. Assessing both the pharmacologically treated and untreated children as well as children with $\mathrm{PH}$ and secondary hypertension, Hanevold et al. found $\mathrm{CH}$ in as many as $16 \%$ of patients, while $\mathrm{EH}$ occurred in $20 \%$ of children [3]. In contrast to our findings, Richey et al., who studied LV geometry in a group of children with $\mathrm{PH}$ at the time of diagnosis and before the initiation of antihypertensive therapy, found $\mathrm{CH}$ and $\mathrm{EH}$ with the same frequency (19.1\%), and NG in $51.5 \%$ of patients. They also observed that patients with EH had a higher DBP compared with other groups [31]. The differences between our results and those of Richey et al. may be explained by racial differences. All our patients were of Caucasian origin, whereas $75 \%$ of the patients evaluated by Richey et al. were of African-American origin. We found higher DBP in patients with $\mathrm{CH}$ than in patients with $\mathrm{EH}$, both at diagnosis and after 1 year of treatment. It corresponds with findings in the Bogalusa Heart Study that DBP in childhood-predicted CH in adulthood [13]. This study also confirmed the correlation between $\mathrm{CH}$ and DBP and with impaired glucose tolerance.

There are no pediatric data concerning the risk associated with the type of LV remodeling. Nonetheless, Border et al. found diastolic dysfunction in as many as $36 \%$ of children with $\mathrm{PH}$, and it mostly affected children with $\mathrm{CH}$ [32]. Because LV remodeling depends on many factors, including duration of hypertension, $\mathrm{CH}$ may also develop in obese patients [33, 34]. This was shown by Daniels et al., who reported that duration of hypertension was significantly longer in children with $\mathrm{CH}$ in comparison with patients with other patterns of LV remodeling [1].

Similar to other studies [35], we did not find any strong relation between BP and LVMi. The relatively small impact of BP on LV may be due to the relatively low absolute values of blood pressure. As discussed previously, although blood pressure values in children with $\mathrm{PH}$ are within the hypertensive range in relation to age and growth, they are relatively low in comparison with those found in secondary hypertension or in hypertensive adults [16]. Second, the range of absolute values of blood pressure observed in our study was relatively narrow.

The TG/HDL ratio is a marker of metabolic abnormalities typical for visceral obesity and hyperinsulinemia. These abnormalities are also typical for adolescents with $\mathrm{PH}$. Hypertriglyceridemia with low HDL-cholesterol concentrations indirectly points to insulin resistance [27]. However, insulin resistance is linked to exposure to other growth factors causing LVH [36]. We found that the main determinants and correlates of RWT are the TG/HDL ratio, $\mathrm{WC}$, and oxidative stress. Although we did not find any relation between insulin or HOMA-IR and RWT, patients whose LV geometry did not normalize or who developed $\mathrm{CH}$ had greater $\mathrm{HbAlC}$ and insulin concentrations during the oral glucose tolerance test. Moreover, they increased insulin secretion after the glucose load.

The third finding of our study is that in children with $\mathrm{PH}$, LVMi and LV geometry can normalize. Although there is a small amount of data on the changes in LVMi during treatment in children with $\mathrm{PH}$, we did not find any data on the changes in LV geometry. Although the prevalence of $\mathrm{NG}$ increased and that of $\mathrm{EH}$ decreased significantly, the prevalence of $\mathrm{CH}$ did not change. Moreover, patients with $\mathrm{CH}$ did not experience lower $\mathrm{BP}$ to the same extent as patients with EH. This suggests that $\mathrm{CH}$ might be more difficult to reverse. One may hypothesize that $\mathrm{CH}$ is a marker of advanced TOD, also causing resistance to antihypertensive treatment. This suggests that the assessment of LV geometry might be valuable for the evaluation of further risk and may be an indication for more intensive treatment.

One of the main limitations of our study is the relatively low number of patients. The low absolute number of patients with $\mathrm{CH}$ and $\mathrm{CR}$ limits the possibility of statistical analysis. Second, because our patients were treated both pharmacologically and with non-pharmacological measures, it is difficult to evaluate the effects of specific treatments. Moreover, we did not monitor adherence to non-pharmacological treatment including sodium intake and physical activity. Similarly, although we treated patients according to guidelines, we used different drugs (ACEi or ARBs). Those limitations are why we could only evaluate determinants of change in LV geometry, but not the effects of specific drugs. Another limitation is the racial and ethnic homogeneity of our patients. For this reason our results cannot be extrapolated to other racial groups. Gender distribution was similar to that of other studies and is typical of $\mathrm{PH}$ in adolescence [1, 31]. However, potential gender-related effects on the evolution of LV geometry should be observed in a larger group of patients. 
Concluding, our results indicate that in Caucasian children with $\mathrm{PH}$, the most prevalent type of LVH is $\mathrm{EH}$. The main determinants of EH are visceral obesity, of $\mathrm{CH}$-insulin resistance. Antihypertensive treatment leads to significant improvement and normalization of LV geometry. However, patients with $\mathrm{CH}$ are less prone to normalized $\mathrm{LV}$ geometry and may require more intensive treatment.

Open Access This article is distributed under the terms of the Creative Commons Attribution Noncommercial License which permits any noncommercial use, distribution, and reproduction in any medium, provided the original author(s) and source are credited.

\section{References}

1. Daniels SR, Loggie JM, Khoury P, Kimball TR (1998) Left ventricular geometry and severe left ventricular hypertrophy in children and adolescents with essential hypertension. Circulation 97:1907-1911

2. Sorof JM, Alexandrov AV, Garami Z, Turner JL, Grafe RE, Lai D, Portman RJ (2003) Carotid ultrasonography for detection of vascular abnormalities in hypertensive children. Pediatr Nephrol 18:1020-1024

3. Hanevold C, Waller J, Daniels S, Portman R, Sorof J (2004) International Pediatric Hypertension Association: the effects of obesity, gender and ethnic group on left ventricular hypertrophy and geometry in hypertensive children: a collaborative study of the International Pediatric Hypertension Association. Pediatrics 113:328-333

4. Litwin M, Niemirska A, Śladowska J, Antoniewicz J, Daszkowska J, Wierzbicka A, Wawer ZT, Grenda R (2006) Left ventricular hypertrophy and arterial wall thickening in children with essential hypertension. Pediatr Nephrol 21:811-819

5. McNiece KL, Gupta-Malhotra M, Samuels J, Bell C, Garcia K, Poffenbarger T, Sorof JM, Portman RJ (2007) Left ventricular hypertrophy in hypertensive adolescents. Analysis of risk by 2004 National High Blood Pressure Education Program Working Group criteria. Hypertension 50:392-395

6. Litwin M, Śladowska J, Antoniewicz J, Niemirska A, Wierzbicka A, Daszkowska J, Wawer ZT, Janas R, Grenda R (2007) Metabolic abnormalities, insulin resistance and metabolic syndrome in children with primary hypertension. Am J Hypertens 20:875-882

7. Sorof JM, Cardwell G, Franco K, Portman RJ (2002) Ambulatory blood pressure and left ventricular mass index in hypertensive children. Hypertension 39:903-908

8. Gutin B, Johnson MH, Humphries MC, Hatfield-Laube JL, Kapuku GK, Allison JD, Gower BA, Daniels SR, Barbeau P (2007) Relationship of visceral adiposity to cardiovascular disease risk factors in black and white teens. Obesity 15:1029-1035

9. Levy D, Garrison RJ, Savage DD, Kannel WB, Castelli WP (1990) Prognostic implications of echocardiographically determined left ventricular mass in the Framingham Heart Study. N Engl J Med 322:1561-1566

10. Verdecchia P, Carini G, Circo A, Dovellini E, Giovannini E, Lombardo M, Solinas P, Gorini M, Maggioni AP; MAVI (Massa Ventricolare sinistra nell'Ipertensione) Study Group (2001) Left ventricular mass and cardiovascular morbidity in essential hypertension: the MAVI study. J Am Coll Cardiol 38:1829-1835

11. Koren MJ, Devereux RB, Casale PN, Savage DD, Laragh JH (1991) Relation of ventricular mass and geometry to morbidity and mortality in uncomplicated essential hypertension. Ann Intern Med 114:345-352
12. Muiesan ML, Salvetti M, Monteduro C, Bonzi B, Paini A, Viola S, Poisa P, Rizzoni D, Castellano M, Agabiti-Rosei E (2004) Left ventricular concentric geometry during treatment adversely affects cardiovascular prognosis in hypertensive patients. Hypertension 43:731-738

13. Toprak A, Wang H, Chen W, Paul T, Srinivasan S, Berenson G (2008) Relation of childhood risk factors to left ventricular hypertrophy (eccentric or concentric) in relatively young adulthood (from the Bogalusa Heart Study). Am J Cardiol 101:1621-1625

14. Seeman T, Gilík J, Vondrák K, Simková E, Flögelová H, Hladíková M, Janda J (2007) Regression of left-ventricular hypertrophy in children and adolescents with hypertension during ramipril monotherapy. Am J Hypertens 20:990-996

15. Assadi F (2007) Effect of microalbuminuria lowering on regression of left ventricular hypertrophy in children and adolescents with essential hypertension. Pediatr Cardiol 28:27-33

16. Litwin M, Niemirska A, Śladowska-Kozłowska J, Wierzbicka A, Janas R, Wawer ZT, Wisniewski A, Feber J (2010) Regression of target organ damage in children and adolescents with primary hypertension. Pediatr Nephrol 25:2489-2499

17. National High Blood Pressure Education Program Working Group on High Blood Pressure in Children and Adolescents (2004) The fourth report on diagnosis, evaluation and treatment of high blood pressure in children and adolescents. Pediatrics 114:555-576

18. Lurbe E, Cifkova R, Cruickshank JK, Dillon MJ, Ferreira I, Invitti C, Kuznetsova T, Laurent S, Mancia G, Morales-Olivas F, Rascher W, Redon J, Schaefer F, Seeman T, Stergiou G, Wühl E, Zanchetti A, Society E, European Society of Hypertension (2009) Management of high blood pressure in children and adolescents: recommendations of the European Society of Hypertension. J Hypertens 27:1719-1742

19. Wühl E, Witte K, Soergel M, Mehls O, Shaefer F, German Working Group on Pediatric Hypertension (2002) Distribution of 24-h ambulatory blood pressure in children: normalized reference values and role of body dimensions. J Hypertens 20:1995-2007

20. Urbina E, Alpert B, Flynn J, Hayman L, Harshfield GA, Jacobson M, Mahoney L, McCrindle B, Mietus-Snyder M, Steinberger J, Daniels S, American Heart Association Atherosclerosis, Hypertension, and Obesity in Youth Committee, Ambulatory Blood Pressure Monitoring in Children and Adolescents (2008) Recommendations for standard assessment. A scientific statement from the American Heart Association Atherosclerosis, Hypertension, and Obesity in Youth Committee of the council on cardiovascular disease in the young and the council for high blood pressure research. Hypertension $52: 433-451$

21. Cole TJ, Bellizzi MC, Flegal KM, Dietz WH (2000) Establishing a standard definition for child overweight and obesity worldwide: international study. BMJ 320:1240-1243

22. Sahn DJ, DeMaria A, Kisslo J, Weyman A (1978) Recommendations regarding quantitation in M-mode echocardiography: results of survey of echocardiographic measurements. Circulation 58:1072-1083

23. Devereux RB, Alonso DR, Lutas EM, Gottlieb GJ, Campo E, Sachs I, Reichek N (1986) Echocardiographic assessment of left ventricular hypertrophy: comparison to necropsy findings. Am J Cardiol 57:450-458

24. De Simone G, Daniels SR, Devereux RB, Meyer RA, Roman MJ, de Divitiis O, Alderman MH (1992) Left ventricular mass and body size in normotensive children and adults: assessment of allometric relations and impact of overweight. J Am Coll Cardiol 20:1251-1260

25. Khoury PR, Mitsnefes M, Daniels SR, Kimball TR (2009) Agespecific reference intervals for indexed left ventricular mass in children. J Am Soc Echocardiogr 22:709-714

26. Daniels SR, Meyer RA, Liang Y, Bove KE (1998) Echocardiographically determined left ventricular mass index in normal 
children, adolescents and young adults. J Am Coll Cardiol 12:703-708

27. McLaughlin T, Abbasi F, Cheal K, Chu J, Lamendola C, Reaven G (2003) Use of metabolic markers to identify overweight individuals who are insulin resistant. Ann Intern Med 139:802-809

28. Matthews DR, Hosker JP, Rudenski AS, Naylor BA, Treacher DF, Turner RC (1985) Homeostasis model assessment: insulin resistance and beta-cell function from fasting plasma glucose and insulin concentrations in man. Diabetologia 28:412-419

29. Flynn JT, Alderman MH (2005) Characteristics of children with primary hypertension seen at a referral center. Pediatr Nephrol 20:961-966

30. Drukteinis JS, Roman MJ, Fabsitz RR, Lee ET, Best LG, Russell M, Devereux RB (2007) Cardiac and systemic hemodynamic characteristics of hypertension and prehypertension in adolescents and young adults. The Strong Heart Study. Circulation 115:221227
31. Richey PA, Disessa TG, Somes GW, Alpert BS, Jones DP (2010) Left ventricular geometry in children and adolescents with primary hypertension. Am J Hypertens 23:24-29

32. Border WL, Kimball TR, Witt S (2007) Diastolic filling abnormalities in children with essentials hypertension. J Pediatr 150:503-509

33. Lavie CJ, Milani RV, Ventura HO (2007) Disparate effects of left ventricular geometry and obesity on mortality in patients with preserved left ventricular ejection fraction. Am J Cardiol 100:1460-1464

34. Grossman W (1980) Cardiac hypertrophy: useful adaptation or pathologic process? Am J Med 69:576-584

35. Brady TM, Fivush B, Flynn JT, Parekh R (2008) Ability of blood pressure to predict left ventricular hypertrophy in children with primary hypertension. J Pediatr 152:73-78

36. Lever AF, Harrap SB (1992) Essential hypertension: a disorder of growth with origins in childhood? J Hypertens 10:101-120 